\title{
Solitary hepatic involvement of histologically and clinically indolent chronic lymphocytic leukemia
}

\author{
Yusuke Matsui $^{1}$, Yasuo Miura ${ }^{2 *}$, Akifumi Takaori-Kondo ${ }^{1}$ \\ ${ }^{I}$ Department of Hematology and Oncology, Kyoto University Graduate School of Medicine; ${ }^{2}$ Department of Transfusion \\ Medicine and Cell Therapy, Kyoto University Hospital
}

Received 2016/7/12; accepted 2016/8/3; released online 2016/12/25

Keywords: chronic lymphocytic leukemia, liver, biopsy, ultrasound, radiological examinations

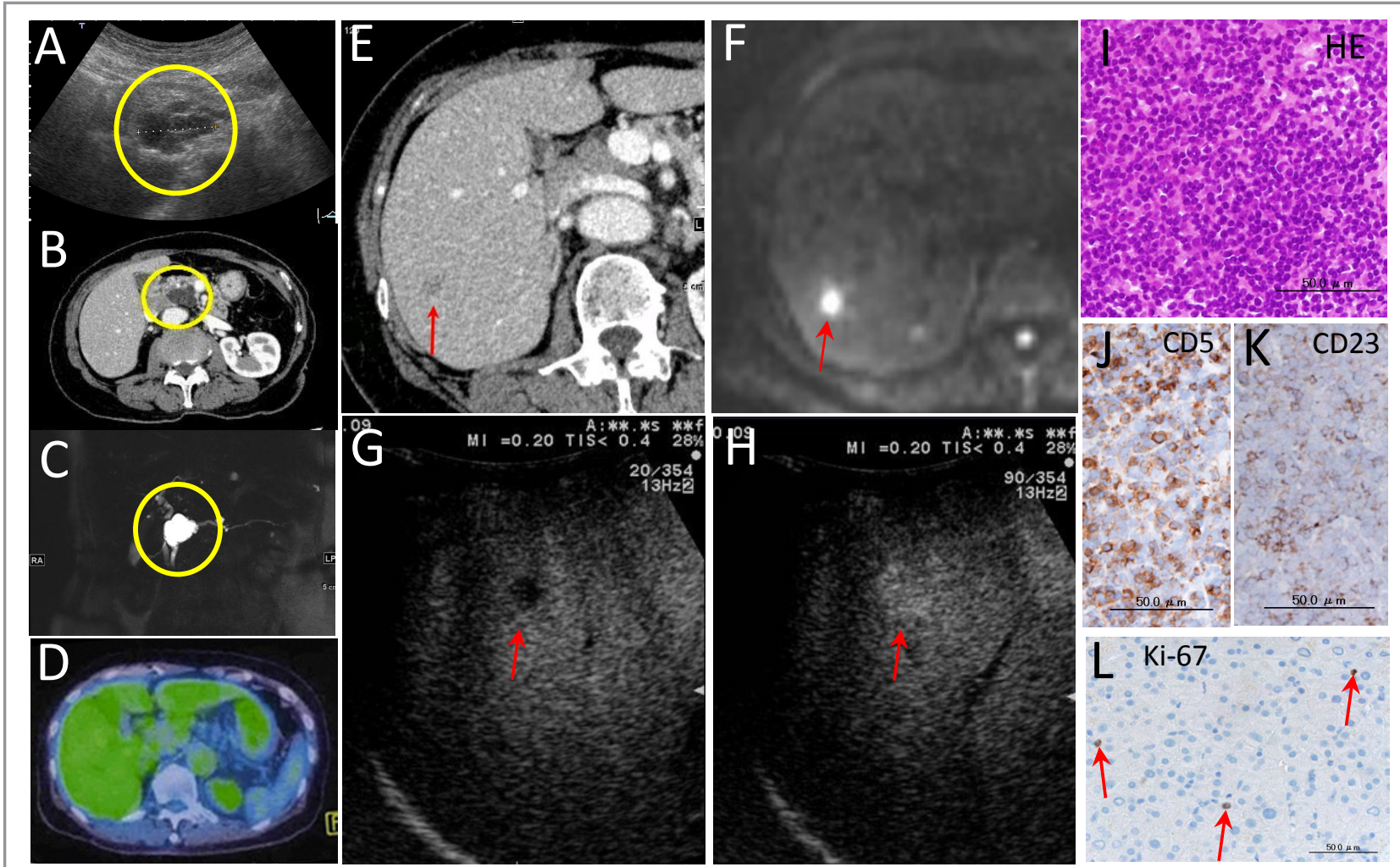

Figure 1. (A-C) Branch-duct type intraductal papillary-mucinous neoplasm. Assessment with an ultrasound (US) (A, yellow circle), computed tomography $(C T)$ scan (B, yellow circle) and magnetic resonance imaging (MRI) (C, yellow circle). (D-L) Solitary hepatic involvement of chronic lymphocytic leukemia. No F-18-fluorodeoxyglucose (FDG) uptake in liver as assessed by an FDG/positron-emission tomography (D). CT scan revealed a small nodule of low-density $(1.2 \mathrm{~cm}$ in diameter) in the right posterior segment of the liver (E, red arrow). On the MRI, the nodule was high-intensity on the diffusion image (F, red arrow). In a contrast enhanced US using Sonazoid, negative uptake in the Kupffer phase (G, red arrow) and enhanced uptake after Sonazoid reinjection ( $H$, red arrow) were observed. Histological analysis on the liver nodule specimen showed a monotonous appearance of small lymphocytes (I, HE staining). Immunohistochemical analysis demonstrated that these lymphocytes were positive for CD5 (J), CD23 (K) with a low Ki-67 labeling index (L, red arrows).

*Correspondence to: Yasuo Miura, $\mathrm{MD}, \mathrm{PhD}$

Department of Transfusion Medicine and Cell Therapy, Kyoto University Hospital 54 Shogoin-Kawahara, Sakyo, Kyoto 606-8507, Japan

e-mail: ym58f5@kuhp.kyoto-u.ac.jp
A 74-year-old female was referred to the hematology department due to persistent leukocytosis. Laboratory findings were as follows: white blood cell count $15.4 \times 10^{9} / \mathrm{L}$ with $39 \%$ 
neutrophils, $60 \%$ lymphocytes, $1 \%$ monocytes and a few basket cells, hemoglobin $14.0 \mathrm{~g} / \mathrm{dL}$, platelets $323 \times 10^{9} / \mathrm{L}$, lactose dehydrogenase $233 \mathrm{IU} / \mathrm{L}$ (normal range 124-226 IU/L) and soluble interleukin-2 receptor $645 \mathrm{U} / \mathrm{mL}$. Flow cytometric analysis on peripheral blood demonstrated that lymphocytes were positive for CD5, CD19 and CD23 surface molecules. Bone marrow examination showed an interstitial infiltrate composed of small lymphocytes with a narrow cytoplasm border and a densely-stained nucleus. No chromosomal abnormalities were found by G-band or FISH analyses. She was diagnosed with histologically indolent chronic lymphocytic leukemia (CLL).

F-18-fluorodeoxyglucose (FDG) positron-emission tomography (PET) was performed for the initial staging of CLL. Uptake of FDG was only observed in the pancreatic head and body mass. Further examinations with an ultrasound (US) (Figure 1A, yellow circle), CT scan (Figure $1 \mathrm{~B}$, yellow circle) and magnetic resonance imaging (MRI) (Figure 1C, yellow circle) confirmed a branchduct type intraductal papillary-mucinous neoplasm, which tend to be highly complicated in non-pancreatic malignancies. ${ }^{1}$ There was no abnormal FDG uptake except for in the pancreatic lesion (Figure 1D). However, the CT scan revealed a small nodule of low-density (1.2 $\mathrm{cm}$ in diameter) in the right posterior segment of the liver (Figure 1E, red arrow). On the MRI, the nodule was of low-intensity on the T1-weighted image, and high-intensity on the diffusion (Figure 1F, red arrow) and T2-weighted images. In a contrast enhanced US using Sonazoid, the nodule exhibited negative uptake in the Kupffer phase (Figure 1G, blue arrow) and enhanced uptake after Sonazoid reinjection (Figure 1H, blue ar- row). Histological analysis on the liver nodule specimen obtained by an ultrasound-guided needle biopsy showed a monotonous appearance of small lymphocytes (Figure 1I). Immunohistochemical analysis demonstrated that these lymphocytes were positive for CD5 (Figure 1J), CD23 (Figure 1K) and negative for CD3, CD10. The percentage of $\mathrm{Ki}-67^{+}$cells was low at $5 \%$ (Figure $1 \mathrm{~L}$ ). Thus, the diagnosis of hepatic involvement of indolent CLL was made.

The extent of FDG uptake in affected lesions is correlated with grade of malignancy in PET examination on CLL. ${ }^{2}$ However, little information is available about image findings of solitary hepatic involvement of histologically and clinically indolent CLL. Our case provides detailed information with CT, MRI, PET and US examinations, which suggested a space-occupying nodule in the hepatic parenchyma with arterial hypervascularity. With respect to correlation with histological findings, a previous study reported that CLL mostly shows infiltration of the portal fields, which deranges the normal hepatic architecture. ${ }^{3}$ There may be heterogeneity in patterns of hepatic involvement of CLL.

\section{REFERENCES}

1. Kawakubo K, Tada M, Isayama H, et al. Risk for mortality from causes other than pancreatic cancer in patients with intraductal papillary mucinous neoplasm of the pancreas. Pancreas 2013;42:687-691.

2. Falchi L, Keating MJ, Marom EM, et al. Correlation between FDG/PET, histology, characteristics, and survival in 332 patients with chronic lymphoid leukemia. Blood 2014;123:2783-2790.

3. Baumhoer D, Tzankov A, Dirnhofer S, et al. Patterns of liver infiltration in lymphoproliferative disease. Histopathology 2008;53:81-90.

\title{
無症候性慢性リンパ性白血病患者に偶然見つかった孤立性肝浸潤病変
}

\author{
松井佑亮 ${ }^{1}$, 三浦康生 ${ }^{2}$, 高折晃史 ${ }^{1}$ \\ ${ }^{1}$ 京都大学大学院医学研究科 血液 - 腫瘍内科学 ${ }^{2}$ 京都大学医学部附属病院 輸血細胞治療部
}

